\title{
Redes de Cooperação de Micro e Pequenas Empresas: mecanismo de desenvolvimento local no Polo Industrial de Juruaia - MG
}

\author{
Cooperation Network of Micro and Small Enterprises: mechanism for local \\ development in the Industrial Pole of Juruaia - MG
}

\begin{abstract}
Resumo
A fim de enfrentarem os desafios e proporcionar o desenvolvimento, uma das principais características atuais das organizações é a necessidade de atuarem de forma conjunta e associada. As redes de cooperação muitas vezes são alternativas eficazes para empresas de pequeno e médio porte que tendem a obter espaço num mercado cada vez mais competitivo. Este artigo se baseia em um estudo de caso, que teve como objetivo identificar a importância da formação de redes de cooperação como mecanismo de desenvolvimento local. Essa pesquisa foi realizada na região sul de Minas Gerais em um cluster de micro e pequenas empresas do segmento de confecções de moda intima. $O$ trabalho de campo foi realizado em duas fases: a primeira teve o propósito de identificar a importância da formação de redes de cooperação para as empresas pertencentes ao cluster e a segunda teve o propósito de analisar se a concentração de empresas pode ser considerada como um mecanismo de desenvolvimento local. Como principais resultados, observou-se que a cooperação através da aglomeração entre as empresas permitiu que o cluster se tornasse um propulsor do desenvolvimento local, pois a partir de suas criações houve um crescimento contínuo das empresas e consequentemente do polo em estudo.
\end{abstract}

Palavras-chave: Rede de cooperação, Cluster, Desenvolvimento local, Micro e pequena empresa.

\begin{abstract}
In order to meet the challenges and provide the development, one of the main characteristics of today's organizations is the need to act jointly and associated. Collaborative networks are often effective alternative for small and medium sized companies that tend to get a space market increasingly competitive. This article is based on a case study, which aimed to identify the importance of building networks of cooperation as a mechanism for local development. This survey was conducted in the southern region of Minas Gerais in a cluster of micro and small companies in the apparel underwear. Fieldwork was conducted in two phases: the first aimed to identify the importance of developing cooperation networks for enterprises belonging to the cluster and the second aimed to analyze the concentration of firms can be considered as a mechanism local development. The main results showed that cooperation through the agglomeration between the companies allowed the cluster to become an engine of local development, because from his creations was a continuous growth of business and consequently the pole under study.
\end{abstract}

Keywords: Cooperation network, Cluster, Local Development, Micro and small enterprises.

Fernanda Eliza ${ }^{1}$

${ }^{1}$ Rua Presidente Bernardes, 187, Bairro Rosario, CEP: 37140000, Areado-MG - fernandaeliz@yahoo.com.br 


\section{Introdução}

$\mathrm{C}$ om o mercado cada vez mais acirrado, as empresas buscam alternativas estratégicas para manter-se competitivas. A articulação em rede se apresenta como uma dessas estratégias, muito além daquelas que uma empresa consegue desenvolver isoladamente. A idéia de rede tornou-se associada ao conceito de competitividade, principalmente a partir dos anos 90 e é baseada no pressuposto de que a parceria pode suprir as empresas debilitadas com aquelas competências faltantes (CASSIOLATO; SZAPIRO; LASTRES, 2004).

Muitas empresas procuram associar-se em redes locais como clusters para atuarem de forma conjunta e associada (CANIELS; ROMIJN, 2003). As Micro e Pequenas Empresas (MPE's) quando atuam de maneira isolada enfrentam dificuldades visíveis no mercado, como, acesso a novos clientes e mercados, negociação em preço, vantagem em compra de insumos, marketing, custos em capacitação operacional, tecnologicos, acesso a linhas de créditos e finaciamentos bancarios e a informações sobre valores de exportação de produtos, enfim diversos problemas empresarias não serao exaurido porém seus efeitos podem ser diminuidos ou neutralizado através da ação coletiva entre as as MPE's (ALVES, 2008). Desse modo, com a grande mudança na economia global e a alta competitividade, as MPE's foram induzidas a cooperar entre si; a ameaça fez com estas se unissem formando uma nova estrutura organizacional e inovadora trazendo um novo conceito de relacionamento entre as empresas (OLAVE; AMATO NETO, 2001).

A cooperação traz um conjuto de benefícios que facilitam a encorporação e o desenvolvimento empresarial de forma a promover o compartilhamento de atividades em comum como especialização de mão de obra, negociação direta com o fornecedor,menores custos dos insumos, acesso facilitado a creditos,melhoria de processos e muitos outros fatores que facilitam a permanência da empresa no mercado.

De acordo com Verschoore e Balestrim (2008), a globalização dos mercados, a tecnologia em constante avanço e facilidade de troca de informações, conduziram as grandes tranformações competitivas atuais. Os consumidores hoje exigem competência agrupadas, reunindo flexibilidade e agilidade que uma empresa isolada jamais conseguiria desenvolver tornando a cooperação em rede essencial e sua concretização um diferencial.

O cooperativismo bem como suas consequências aplicam-se de fato diretamente ao desenvolvimento regional, tranzendo crescimento empresarial e consequentemente empregatício, onde a demanda por profissionais chegam a ser escassa partindo assim para contratações em cidades vizinhas.

Com o impacto de mercado,as empresas de pequeno porte (MPE'S) são uma das mais atingidas, afinal estas não possuem estrutura finaceira para competir com grandes marcas tanto nacionais, quanto internacionais, fato este, que justifica o grande número de polarização e redes de cooperação entre setores. Segundo Candido e Abreu (2000), o grande desafio das MPE's é conseguir se manter a ponto de promover o desenvolvimento econômico de uma região. Mas para isso estas empresas necessitam agir de forma inovadora para os novos desafios que a competitividade atribui.

Fica claro que a cooperação entre empresas dentro de um cluster ou aglomerados industriais promovem um mecanismo de desenvolvimento local. Sendo assim, é evidente as formas de difusão de vantagens competitivas, entre as organizações pertencentes a este tipo de aglomeração.

Com objetivo identificar a importância da formação de redes de cooperação como mecanismo de desenvolvimento local este artigo visa aprimorar e esclarecer aos pequenos e médios empreededores os benefícios e as dificuldades de se trabalhar dentro de um cluster, foco este que impulsionou os autores a desevolver este artigo.

\section{Revisão Teórica}

\subsection{Redes de Cooperação}

Nos últimos anos, estudiosos têm realizado estudos sobre estratégias de desenvolvimento econômico e social realçando o papel das MPE's e estas configuradas sob a óptica das redes de cooperação. Não existe um único conceito para definir as redes, mas é aceito que sua operacionalização se dá por meio de colaboração e esta tem variadas explicações teóricas para justificar sua existência (OLAVE; AMATO NETO, 2001; SUZIGAN et al., 2004; LATRES et al., 2003).

Em regiões onde há concentração de empresas do mesmo seguimento é comum a formação de redes de cooperação e consequentemente benefícios multivariados dentre as empresas associadas. $\mathrm{O}$ fato proporciona mão de obra qualificada, produtos semi-acabados, maquinários mais baratos além da vendas centralizadas, afinal clientes e interessados estão certos que ali encontrarão produtos que atendem sua necessidade rapidamente (RAMBO; RUPPENTHAL, 2004).

As organizações que pertencem a redes de empresas participam e colaboram de forma recíproca, estabelecendo vantagens econômicas e estratégias, além do compartilhamento de meios produtivos e investimento em tecnologia

Segundo Candido e Abreu (2000) as formas organizacionais baseado na cooperação e elos, são alternativas viáveis para resolver diversos problemas ocorridos nas MPE'S. Assim, de forma conjunta as empresas tendem a obter maior sobrevivencia, crescimento e competitividade,podendo concorrer com empresas maiores e destacar perante ao mercado global.

Porter (1991) apresenta um importante assunto a ser pensado em termos de cooperação e competividade 
para o desenvolvimento, ele atenta que as empresas mutuamente dependentes podem ter bons lucros agindo independente ; porem se todas agirem e pensarem somente proprio interesse elas podem rebeliar contra a cooperação e acabar em situações ainda piores.

O foco das redes de cooperação é no entanto atribuir fatores que levam a permanecer no ambiente competitivo atribuindo tais beneficios a uma unica estrutura organizada por ações unanimes porém descentralizadas que permitam ganhos competitivos a todas empresas envolvidas (RAC, 2008).

Para que este tipo de cooperação funcione de forma eficaz é preciso seguir um código de ética, assim como fidelidade, ter responsabilidade com o cumprimento dos deveres, preços justos a fim de ter uma concorrência equilibrada. Afinal o objetivo da rede além do compartilhamento é a promoção do setor no qual se especifica a rede.

\subsection{Clusters de MPE's}

Os clusters são vitais para o desenvolvimento regional dado que levam ao aumento da produtividade, desempenho, inovação e ao desenvolvimento empresarial (NOVELLI et al, 2006). Como consequência, diversas organizações mundiais como a OCDE, UNIDO, Banco Mundial, UNCTAD, Comissão Europeia, SEBRAE, IBGE e EMBRAPA estão a avaliar e a usar os clusters como meio para alcançar o desenvolvimento local.

Porter (1998) define clusters como uma concentração de empresas especializadas em algum setor industrial, localizadas em uma area geografica proxima o que acentua a competitividade, porem permite a troca de informações e inovações tecnologicas caracterizando a cooperação.

Galão et al. (2008) acreditam que os clusters tambem chamado de aglomerados ou arranjo produtivos envolvem empresas de pequeno, medio e grande porte o que traz crescimento para a região pois os envolvidos na cadeia produtivida dos bens ali fabricados acabam migrando para a região trazendo crescimento economico.

Os clusters começam com uma grande empresa ou uma concentração de empresas do mesmo setor que passam a buscar e identificar fornecedores e distribuidores para atender a demanda. As empresas envolvidas no cluster devem buscar por informações, que na maioria das vezes são fornecidas por associações e instituições como universidades, centros de tecnologia, entre outros. As empresas também devem buscar parcerias com o governo afim de obter investimentos em infra-estrutura (PORTER, 1999).

Na visão de Neckel et al.( 2010) a abertura de novas empresas em determinada área geográfica, caracterizando os aglomerados industriais se torna cada dia mais comum e tem como característica principal a especialização em determinada atividade industrial e na maioria das vezes a abertura de empresas que complementam o setor principal do aglomerado a fim de obter vantagem competitiva.

Para Porter (1992) a eficiência e a especialização das empresas estão ligadas diretamente na procura e implantação de inovações. O aglomerado de empresas é visto como uma fonte de inovação que permite as empresas um vinculo facilitado com os fornecedores, a troca de informaçoes, a comperação e a competição entre rivais.

A produtividade é apontada como fator primordial para o sucesso de um cluster, pois o poder de negociação cresce o que permite acesso facilitado a insumos especificos, redução no custo da materia prima, especialização da mão-de-obra. Ainda, agregam vantagem competitivas como a especialização da produção que gera redução de custos o que permite produzir mais gastando menos (GALÃO et al., 2008).

Contudo, as MPE's encontram dificuldades para competir isoladamente, com isso os aglomerados são vistos como forma de minimizar os problemas encontrados no dia a dia. A ação em conjunta das MPE's dentro dos aglomerados traz diversos benefícios tais como: a redução no custo da materia-prima, especialização da mão-de-obra, acesso a insumos de boa qualidade, busca por informações, acesso a treinamentos e inovações com preços reduzidos, aumento da produtividade, entre outros (LIMA;CARVALHO,2010)

\subsection{Desenvolvimento Local}

A partir do grande avanço da globalização no mundo o termo "desenvolvimento local" tornou-se um novo método de desenvolvimento, onde identifica-se diretamente com o "perfil" do território, usufruindo de suas particularidades, beneficiando da cultura e do conhecimento ali desenvolvido (PAULA, 2009)

Rodrigues e Simões (2004) acreditam que para haver o desenvolvimento social e econômico é preciso ter uma boa construção estratégica. Já Paula (2009) acredita que as pessoas são a base para o desenvolvimento, partindo do ponto em que estes se sentem obrigados a colaborar para a melhoria não somente da economia mais também do ambiente onde vivem.

As organizações necessitam de uma estrutura de suporte para conseguir se manter no mercado, portanto é preciso estabelecer um vinculo entre as empresas e o município, permitindo uma melhoria do ambiente em que estas estão inseridas fazendo com que o desenvolvimento do município se torne um sucesso próprio de cada empresa (TEIXEIRA; VITCEL; BEBER, 2007).

Para que haja um crescimento intensivo fatores básicos são essenciais, entre eles, o estado, o mercado e a sociedade. Estes são vistos como forma de desenvolvimento, afinal o estado representa o apoio governamental, o mercado são as organizações e por fim a sociedade que é o agente básico para a promoção do crescimento dos demais. (PAULA, 2009)

Na economia brasileira as MPES representam a maior parcela do mercado e são vistas como forma de garantir o desenvolvimento do país. O Serviço Brasileiro de Apoio 
às Micro e Pequenas Empresas (SEBRAE) é hoje o maior programa de incentivo ao desenvolvimento das MPES nacionais. Na cidade em estudo, o SEBRAE encontra-se atuante através das capacitações, treinamentos, visitas técnicas, além do incentivo e monitoramento para a formação de associações empresariais (SEBRAE, 2010)

Em 1997, a prefeitura municipal de Juruaia e os empresários da cidade se uniram com a iniciativa de promover o polo industrial. Assim foi iniciada a construção de uma associação que além da união de empresas também promovesse a divulgação de um mercado que estava alavancando a economia local da cidade. A ACIJU - Associação Comercial e Industrial de Juruaia é hoje uma propulsora da realização da Feira de lingerie de Juruaia - FELINJU, sendo esta considerada uma forte ferramenta de divulgação da cidade que é conhecida como a "capital da lingerie" além de atrair vendas localizadas do produto (ACIJU, 2010).

Além desta iniciativa da prefeitura e empresários, no ano de 2008, o SEBRAE considerado como o principal órgão de incentivo as MPES, levou a ideia de se criar uma central de negócios na cidade de Juruaia. Com a necessidade de se organizar foram iniciadas reuniões semanais entre os empresários, com apresentação de ferramentas organizacionais capazes de facilitar e trazer benefícios para todos os associados. Com o passar do tempo, o grupo ganhou uma identidade própria hoje conhecida como Toque Brasil. A Toque Brasil trouxe benefícios relevantes a cidade, como, compras conjuntas, negociação com prestadores de serviços, divulgação da marca da associação e das empresas (algo que sem a cooperação não seria possível, devido a altos custos), fortalecimento do polo, acesso aos mais renomados profissionais da área, incentivo a capacitação através de cursos e palestras, além do fortalecimento da relação entre fornecedores, prestadores de serviços e associados; fatores estes que trouxeram desenvolvimento para todos. (TOQUE BRASIL, 2012; SEBRAE, 2009).

Outro fator inerente ao desenvolvimento de uma região são as instituições de ensino e centros de apoio tecnológicos, que trazem para a região a qualificação da mão de obra local, inovação e também a preparação dos jovens para o mercado de trabalho. (GRAPEGGIA; MINUZZI; LEZANA, 2005). Os aglomerados e as universidades necessitam trabalhar em conjunto, afinal os acadêmicos possuem um vasto conhecimento, que através dos estudantes que se veem imerso ao mercado de trabalho, podem ser transmitidos às organizações, fazendo uma ligação entre a pratica e a teoria, permitindo a empresa por sua vez ganhar conhecimento técnico implementado pelo colaborador que atualiza a organização com as tendências de mercado além de facilitar o acesso as ferramentas de qualidade. (GRAPEGGIA; MINUZZI; LEZANA, 2005).

Grapeggia, Minuzzi e Lezana $(2005$, p.9) argumentam que: "a universidade tem a responsabilidade de formar uma massa crítica altamente especializada que interfira no desenvolvimento socioeconômico de sua região, alcançando um considerável progresso social".

Para haver desenvolvimento é preciso que haja cooperação e confiança entre as partes interessadas, redes e democracia, afinal agentes externos agindo isoladamente não são propulsores do desenvolvimento local. O crescimento econômico e social gera uma grande valorização recíproca entre as pessoas e o território promovendo de forma eficaz a perspectiva de progresso de uma determinada região.

\section{Métodos da Pesquisa e Análise dos Da- dos}

O método de pesquisa utilizado neste trabalho foi o estudo de caso através da pesquisa qualitativa, que segundo Lakatos e Marconi (2010) é um tipo de pesquisa que apresenta aspectos da complexidade do comportamento humano, sendo possível verificar mais detalhadamente investigações, hábitos, atitudes e comportamento. $\mathrm{O}$ trabalho foi desenvolvido na região sul de Minas Gerais em um cluster de micro e pequenas empresas do segmento de confecções de moda íntima. O objetivo dessa pesquisa foi identificar a importância da formação de redes de cooperação como mecanismo de desenvolvimento local.

O trabalho de campo foi realizado em duas fases: a primeira fase teve o propósito de identificar a importância da formação de redes de cooperação para as empresas pertencentes ao cluster e a segunda fase teve o propósito de analisar se a formação da rede de cooperação pode ser considerada como um mecanismo de desenvolvimento local.

A pesquisa classifica-se como uma pesquisa qualitativa na qual o pesquisador tem por objetivo identificar o fenômeno em estudo a partir das informações colhidas com as pessoas que estão envolvidas no caso, levando em consideração todos os pontos de vista relevantes. (GODOY, 1995).

Fez-se o uso de entrevistas e observação para a coleta de dados. As entrevistas foram realizadas nas duas principais associações atuantes em Juruaia/MG com os responsáveis pelos direcionamentos organizacionais e com seis proprietários de empresas pertencentes às associações. A escolha dessa amostra teve a intenção de realizar um estudo entre os três diferentes portes de empresas (micro, pequena e média). Trabalhar com um número maior de empresas não foi possível nesse momento devido ao propósito de aprofundar e fazer análises qualitativas sobre a amostra escolhida.

\subsection{Primeira Fase}

O propósito desta primeira fase foi identificar a importância da formação de redes de cooperação para as empresas pertencentes ao cluster.

Durante o trabalho de campo, identificou-se que a 
cidade de Juruaia conta com mais de 70 lojas formais de confecções atuantes no ramo de moda íntima, sendo que a produção total destas empresas é responsável por aproximadamente $15 \%$ das peças íntimas produzidas no país. Desse modo, segundo o entrevistado, com o grande aumento de empresas, houve a necessidade de se organizarem e criarem associações, a fim do crescimento interno, além de obter maiores vantagens competitivas.

As informações foram coletadas nas duas principais associações atuantes em Juruaia, sendo elas a ACIJU e a Toque Brasil.

A ACIJU surgiu da necessidade de promover o polo, levando em conta que as empresas ali concentradas precisavam de investimentos na divulgação da cidade. Para o entrevistado, ficou evidente a necessidade de agregar cada vez mais uma quantidade maior de associados para facilitar o vinculo com entidades que promovessem e apoiassem aglomerados de pequenas e medias empresas. Desse modo, verificou-se que no aglomerado em estudo há a atuação dos órgãos do SEBRAE, FIEMG e SENAC que apoiam e levam informações úteis para a permanência das empresas no setor, além de oferecerem treinamentos, visitas técnicas e acesso facilitado a feiras e a congressos do setor.

Segundo o entrevistado, a união das empresas firmouse no primeiro trabalho desenvolvido em conjunto com a prefeitura. Esse trabalho foi a criação e realização da FELINJU - Feira de Lingerie de Juruaia, fruto de confiança e união cooperada, com o intuito do beneficiamento não somente dos envolvidos com a associação, mas de toda a cidade.

Vale ressaltar que a realização da FELINJU trouxe grandes vantagens para o cluster. $\mathrm{O}$ aumento na quantidade de visitantes na cidade aumentou a comercialização dos produtos, a chegada de novos fornecedores, o fechamento de novas parcerias e principalmente a promoção do polo através das inúmeras divulgações que são realizadas.

Observou-se que a partir da rede de cooperação as empresas em parceria com as associações criaram outros eventos na cidade para aumentar a comercialização de seus produtos, proporcionando assim um desenvolvimento acentuado. Desse modo, nota-se que a concentração de empresas trouxe benefícios multivariados a partir da cooperação entre as empresas. Como benefícios, pode-se citar os treinamentos para funcionários, visitas técnicas, palestras, acesso facilitado a consultores de diversas áreas, além de facilitar a aplicação de ferramentas úteis à qualidade da empresa e do produto.

Contudo, identificou-se alguns problemas mais comuns enfrentados pelas pequenas e médias empresas da região, tais como: baixo poder de negociação com fornecedores; incapacidade de atender grandes magazines; falta de estratégia com relação a abordagem aos clientes; falta de capacitação para os cargos gerenciais; falta de controle interno, mediante a produção e administração da empresa; falta de equilibro em termos conceituais sobre seus empreendimentos; falta de um software específico que se adéqua as reais necessidades das empresas e a falta de normalização com relação as facções (empresas que terceirizam o corte e a costura).

Foi observado que os empresários a fim de permanecerem no mercado competitivo, se uniram em uma única estrutura, criando a central de negócios com ações unânimes que permitem ganhos competitivos a todas as empresas envolvidas. Esta central de negócios têm como função negociar com fornecedores, realizar compras em conjunto para todas as empresas participantes (fato este que reduziu os valores das matérias primas em até $20 \%$ nos custos dos insumos no aglomerado), a busca de novos fornecedores, a contratação de agências para realizar estudos de mercado, a realização de treinamentos ou busca por profissionais experientes para diagnosticar e apontar problemas das empresas e a capacitação de mão de obra.

Outra vantagem competitiva apontada pelos entrevistados é a troca de experiências entre as empresas pertencentes à rede de cooperação. Evidenciou-se que as empresas enfrentam problemas e dificuldades similares, na qual unidas conseguem chegar à resolução dos problemas.

\subsection{Segunda Fase}

O propósito da segunda fase foi analisar se a concentração de empresas pode ser considerada como um mecanismo de desenvolvimento local.

Foi identificado que a partir da aglomeração das empresas, a cidade se desenvolveu fisicamente e economicamente, podendo notar que houve o fortalecimento do comércio local, o aumento na oportunidade de emprego, a centralização de atacados e indústrias de matéria prima que oferecem insumos utilizados na fabricação das peças, a abertura de lojas especializadas em máquinas e acessórios para a produção além de prestadoras de serviço, que auxiliam na manutenção do maquinário e na produção das peças.

Outro ponto observado foi que através das associações as empresas se engajaram cursos de capacitação que foram disponibilizados para os empregados aumentando assim o nível de conhecimento das pessoas.

Como consequência do aumento da cidade, observou-se que o nível de conhecimento das pessoas também aumentou; funcionários e até mesmo os proprietários passaram a buscar uma capacitação mais específica de suas funções.

Também foi observado que as empresas pertencentes a central de negócios, criaram um mecanismo que oferece vantagens aos seus integrantes, que tem por objetivo identificar os problemas em comum enfrentados nas áreas de vendas, administrativo e produtivo. Esse mecanismo consiste em filtrar os métodos e ferramentas implantados, a fim de compartilhar conhecimento nas organizações. 
Durante o trabalho de campo, observou-se outro fator inerente ao desenvolvimento do cluster é a parceria com a instituição de ensino, que traz para a região a qualificação da mão de obra local, inovação e também a preparação dos jovens para o mercado de trabalho, conforme apontado por Grapeggia et al. (2005).

É importante ressaltar que a concentração de empresas é considerada como um mecanismo de desenvolvimento local para a cidade de Juruaia, pois trouxe benefícios relevantes a cidade, como fortalecimento do comercio local, o aumento de empregos, a abertura de novas lojas, a vinda de atacados para oferecer insumos para a produção das peças, a abertura de indústrias que produzem matéria prima utilizadas nos produtos fabricados, a abertura de lojas especializadas em máquinas de costura e em acessórios para as lojas, além da abertura de restaurantes e hotéis. Também pode destacar que as empresas facilitou o acesso a treinamentos e a cursos de capacitação aumentando assim o nível de conhecimento das pessoas.

Desse modo, conclui-se que no cluster pesquisado existe a cooperação simultânea entre as empresas e o município, trazendo um conjunto de benefícios que bens estruturados permitem um crescimento econômico.

\section{Considerações Finais}

Percebe-se que no cluster pesquisado, a partir da cooperação, as empresas conseguiram alcançar grandes vantagens competitivas, o que permitiu fortalecimento das organizações e consequentemente do Polo.

Com a união das empresas houve um crescimento da cidade, e o fortalecimento da economia, porém nem todas as empresas acreditam que é necessário participar das associações. Contudo, este é um desafio que existe no cluster; outro ponto identificado na pesquisa, é que apesar da cidade investir na estrutura física, ainda necessita de muitas melhorias para atender de forma eficaz as necessidades que as empresas precisam para receber com mais qualidade seus clientes, com relação a hotéis, restaurantes, estacionamentos, entre outros.

Vale considerar que o cluster é hoje um dos mecanismos de aumento da criação de micro e pequenas empresas, afinal a concentração de empresas permitiu ganhos competitivos e estratégicos para todos os envolvidos. Ainda, a cooperação entre as empresas permitiu uma troca de experiência e um poder inerente de busca por novos benefícios, permitindo acessos facilitados e crescentes investimentos no setor desenvolvido.

Para a permanência e fortalecimento das micro e pequenas empresas no mercado regional, fica evidente a busca por mais empresas associadas. Afinal, quanto maior a quantidade de empresas envolvidas, maior será o poder adquirido no mercado nacional e internacional.

Por fim, percebe-se que hoje o cluster é uma das grandes alternativas viáveis para a sobrevivência e cres- cimento das micro e pequenas empresas em meio a um mercado altamente exigente e competitivo.

\section{Agradecimentos}

Agradecemos primeiramente a Deus por ter nos dado saúde e força para superar as dificuldades.A nossa orientadora Gyselle Ricci, pelo empenho dedicado à elaboração deste trabalho. Aos nossos pais, irmão e a todos que direta ou indiretamente fizeram parte da nossa formação, o nosso muito obrigado.

\section{Referências}

ACIJU- ASSOCIAÇÃO COMERCIAL E INDUSTRIAL DE JURUAIA. Capital da Lingerie. Disponível em:< http://www.aciju.com.br/fe linju>. Acesso em: 03 Abr. 2012.

ALVES, C. A. O papel das relações na formação de redes de pequenas e médias empresas: um estudo de caso na indústria de mídia exterior. V ENCONTRO DE ESTUDOS SOBRE EMPREENDEDORISMO E GESTÃO DE PEQUENAS EMPRESAS, 5.,2008. São Paulo. Anais...São Paulo,2008.

CANDIDO, G. A.; ABREU, A. F. de. Aglomerados industriais de pequenas e medias empresas como mecanismo para promoção de desenvolvimento regional. READ - Revista Eletrônica de Administração, Porto Alegre,v. 6, n. 6, 2000.

CANIELS; M.; ROMIJN, H. SME clusters, acquisition of technological capabilities and development: concepts, practices and police lessons. Journal of Industry, Competition and Trade, v. 3, n. 3, p. 187210; Sept. 2003.

CASSIOLATO, J. E.; LASTRES, H. M.M. O foco em arranjos produtivos e inovativos locais de micro e pequenas empresas. In: Arranjos Produtivos Locais: uma nova estratégia de ação para o Sebrae. Rede de Pesquisa em Sistemas Produtivos e Inovativos Locais. 2004. p.1-10.

CRISES E OPORTUNIDADES. Politicas de apoio ao desenvolvimento local. Disponível em: <http:// criseoportunidade.wordpress.com/2009/05/09/ politicas-de-apoio-ao-desenvolvimento-localjuarez-de-paula/>. Acesso em: 29 Abr. 2012.

GALÃO, F. P.; CHIUSOLI, C. L.; PESSOA, D. A. M.; ROGEL, J. C.; SILVA, V. A. da. Arranjos produtivos locais e suas influências no desenvolvimento da 
economia regional. Gerenciais, São Paulo, v. 7, n. 1, p. 13-20, 2008.

GODOY, A. S. Pesquisa qualitativa: Tipos fundamentais. RAE- Revista de Administração de Empresas, São Paulo, v. 35, n.3, p.20-29, 1995.

GRAPEGGIA, M.; MINUZZI, J.; LEZANA, A. G. R. O papel das universidades no desenvolvimento local como suporte para redes de pequenas empresas, v.12, 2005, Bauru. Anais... Bauru, 2005.

LAKATOS, E. M.; MARCONI, M. DE ANDRADE. Metodologia Científica. 4. ed. São Paulo: Atlas,2010

LASTRES ,H. M. M.;CASSIOLATO, J. E. Novas politicas na era do conhecimento: $\mathrm{O}$ foco em arranjos produtivos e inovativos locais. Parcerias estratégicas, 2003. Rio de Janeiro. Anais...Rio de Janeiro,2003

LIMA, G. B, CARVALHO, D. T. de. Clusters industriais com enfoque em internacionalização de empresas: uma pesquisa exploratória nas vinícolas da região de Bento Gonçalves - RS. FACEF Pesquisa, Franca, v. 13, n. 3, p. 378-392, 2010.

NECKEL, A. R.; HOFFMANN, V. E.; SCHOREDER, L. Recursos compartilhados como fonte competitiva em empresas aglomeradas territorialmente: um estudo na indústria têxtil da região de Rio do Sul (SC). Americana de Estratégia- RIAE, São Paulo, v. 9, n. 1, p. 127-151, jan./abr.2010.

NOVELLI, M.; SCHMITZ, B.; SPENCER, T. Networks, clusters and innovation in tourism: A UK experience. Tourism Management, v. 27, p.11411152, 2006.

OLAVE, M. E. L.; AMATO, J. Neto. Redes de cooperação produtiva: uma estratégia de competitividade sobrevivência para pequenas e médias empresas. Gestão e Produção, São Paulo, v.8, n.3, p. 289-303, dez. 2001.

PORTER, M. E. On Competition: estratégias competitivas essenciais. Rio de Janeiro: Campus, 1998.

PORTER, M. E. Competição: estratégias competitivas essenciais. Rio de Janeiro: Campus, 1999.

PORTER, M. E. Vantagem competitiva: criando e sustentando um desempenho superior. Rio de Janeiro: Campus, 1992.

PORTER,M. E. Estratégia Competitiva. Rio de janeiro:
Campus, 1991.

RAMBO, J. A.; RUPPENTHAL, J. E. As redes de cooperação no contexto do desenvolvimento local e regional. ENCONTRO NACIONAL DE ENGENHARIA DE PRODUÇÃO, 24, 2004, Florianópolis. Anais... Florianópolis,2004.

RODRIGUES, C. G. SIMÕES, R. Aglomerados industriais e desenvolvimento socioeconômico: uma análise multivariada para Minas Gerais. Ensaios FEE, Porto Alegre, v. 25, n. 1, p. 203-232, 2004.

SEBRAE - Serviço Brasileiro de Apoio às Micro e Pequenas Empresas. Centrais de negócios 2009. Local: Belo Horizonte, 2009.

SEBRAE - Serviço Brasileiro de Apoio às Micro e Pequenas Empresas. Aumentar participação das Micro e Pequenas empresas na economia deve ser prioridade. Disponível em: <http://revistapegn. globo.com/Revista/Common/0,EMI17387617180,00AUMENTAR+PARTICIPAÇÃO+DAS+MIC RO+E+PEQUENAS+EMPRESAS+NA+ECONOMIA +DEVE+SER+PR.html>. Acesso em: 02 Abr. 2012.

SUZIGAN, W.; FURTADO, J.; GARCIA, R.; SAMPAIO, S. Sistemas locais de produção: mapeamento, tipologia e sugestões de políticas. Revista de Economia Aplicada. v. 24. n. 3, 2004.

TEIXEIRA, E. B.; VITCEL, M. S.; BEBER, M. C. Cooperação estratégica, redes de cooperação e desenvolvimento regional: o caso Unijuí/Sedai. Desenvolvimento em Questão, Ijuí, v. 5, n. 10, p. 187-210, 2007.

TOQUE BRASIL. Os objetivos da Toque Brasil. Disponível em: <http://www.toquebrasil.com.br/>. Acesso em: 03 Abr.2012.

VERSCHOORE, J. R.; BALESTRIM, A. Fatores relevantes para estabelecimento de redes de cooperação entre empresas do Rio Grande do Sul. RAC-Revista de Administração Contemporâneas, Curitiba, v. 12, n. 4, p. 1043-1069, Out. /Dez. 2008. 